\title{
Breastfeeding Education: A Physician and Patient Assessment
}

\author{
J. M. Stolzer ${ }^{1}$ and Syed Afzal Hossain ${ }^{2}$ \\ ${ }^{1}$ Family Studies Department, University of Nebraska-Kearney, Otto Olsen, 205 D, Kearney, NE 68849, USA \\ ${ }^{2}$ Department of Math and Statistics, University of Nebraska-Kearney, Kearney, NE 68849, USA \\ Correspondence should be addressed to J. M. Stolzer; stolzerjm@unk.edu
}

Received 12 February 2014; Revised 11 May 2014; Accepted 11 May 2014; Published 1 June 2014

Academic Editor: Ross Flom

Copyright (C) 2014 J. M. Stolzer and S. A. Hossain. This is an open access article distributed under the Creative Commons Attribution License, which permits unrestricted use, distribution, and reproduction in any medium, provided the original work is properly cited.

\begin{abstract}
In the study presented here, Likert scaled surveys derived from the Surgeon General's Blueprint for Action on Breastfeeding (2000) were mailed to 400 practicing physicians in a Midwestern state to assess medical school breastfeeding education. In addition, 500 surveys were mailed to women in the same Midwestern state who had given birth within the last year to determine what type of breastfeeding information they were receiving from their attending physicians. The purpose of this study is to analyze physician breastfeeding education and to ascertain if the data collected from the physicians is congruent with the data collected from the women who had recently given birth. Results of this study indicate that while the majority of physicians reported sufficient levels of breastfeeding education while in medical school, women participating in this study reported that they did not receive compendious breastfeeding information from their attending physicians.
\end{abstract}

\section{Introduction}

The United States Department of Health and Human Services [1] has clearly stated that breastfeeding rates must increase if we are to be successful at reducing both pediatric and maternal morbidity and mortality rates in America. Research conducted over the last few decades has confirmed that physicians play a pivotal role in increasing breastfeeding initiation and duration rates by informing their female patients of the numerous benefits associated with breastfeeding and by providing factual information about the risks associated with formula feeding [1-3]. According to the Surgeon General of the United States, "If $90 \%$ of U.S. families followed guidelines to breastfeed exclusively for six months the United States would save 13 billion annually from reduced direct medical and indirect costs and the cost of premature death. If $80 \%$ of U.S. families complied, 10.5 billion per year would be saved" (p. 3).

Decades of epidemiological data has confirmed that human milk is far superior to infant formula and it is an undisputed fact that observable and quantifiable differences can be detected when comparing breastfed children with their artificially fed cohorts $[1,2,4]$. Research confirms that children who are breastfed are significantly less likely to suffer from eczema, gastrointestinal infection, respiratory infection, allergies, asthma, diarrhea, botulism, ear infection, bacterial meningitis, urinary tract infection, cancer, bowel disease, diabetes, liver disease, and sudden infant death syndrome (SIDS) [1, 2, 5-7]. Furthermore, hospital admission rates and prescription drug use are lower in breastfed populations, and data confirms that breastfeeding significantly reduces infant mortality $[1,8,9]$.

Breastfeeding impacts not only childhood morbidity and mortality rates, but adolescent and adult pathology as well $[1,10,11]$. Individuals who were formula fed in childhood suffer from higher rates of obesity, inflammatory bowel disease, Crohn's disease, celiac disease, diabetes, multiple sclerosis, cancer, heart disease, high cholesterol, and allergies $[1,2,5,12,13]$. In spite of the common misperception that breastfeeding is protective only during the infancy stage, numerous published data sets have indicated that the benefits associated with breastfeeding can be detected throughout the 
life course $[1,2,14,15]$. According to the Surgeon General of the United States, exclusive breastfeeding and longer durations of breastfeeding have been associated with the most statistically significant positive health outcomes [1].

Data have shown that breastfeeding significantly impacts maternal pathology as well. According to published medical data, women who breastfeed have lower rates of ovarian, breast, and endometrial cancers $[1,2,16,17]$. In addition, women who were breastfed for 2 years or longer during childhood have a $25 \%$ lower incidence of breast cancer than women who were formula fed $[2,18]$. There is also scientific evidence which confirms that the hormonal changes that occur in a woman's body during lactation (i.e., the production of oxytocin and prolactin) increase self-confidence, lower anxiety and depression, decrease mood swings, and increase mother-child bonding $[1,19,20]$.

Lactation has also been associated with reduced hemorrhaging, uterine involution, and postpregnancy weight loss $[1,2]$. Interestingly, decades of scientific data indicate that elevated oxytocin levels in lactating females have been significantly correlated with nurturing behaviors such as wanting to remain in close physical proximity to one's offspring. Furthermore, data indicates that oxytocin induces an overall well-being and induces feelings of serenity and bliss $[1,14,21-$ 23]. According to the United States Department of Health and Human Services [1], exclusive breastfeeding and longer durations of breastfeeding are associated with better overall maternal health outcomes.

A review of the literature confirms the association between breastfeeding and anovulation as breastfeeding suppresses ovarian cyclicity postpartum and has been documented to induce lactational infertility $[2,24,25]$. Epidemiological data indicates that it is the duration of breastfeeding, the frequency of nursing, and the intensity of the child's sucking behavior that are most highly correlated with the absence of ovulation in lactating humans $[19,26,27]$. However, the literature suggests that culturally constructed breastfeeding practices may in fact negate the contraceptive effects of breastfeeding. These practices include separating mother and infant soon after birth, the use of artificial nipples, pumping, early introduction of solid foods, uni-sleeping practices, scheduled breastfeeding, premature weaning, pacifier use, formula supplementation, and the abandonment of childled nursing $[24,28,29]$. In spite of the numerous cultural practices that impede the contraceptive effects of breastfeeding, the fact remains that intense, frequent, and exclusive breastfeeding is a highly effective means of contraception and has reduced fertility rates worldwide $[2,24-26]$.

\section{The Study}

Research confirms that physicians who work closely with women and children (i.e., family practitioners, obstetricians/gynecologists (OB/GYN's), and pediatricians) play a pivotal role in increasing breastfeeding initiation and duration rates $[2,29,30]$. The aims of the study presented here were to (1) analyze physician breastfeeding education/knowledge and (2) determine if women participating in this study were receiving accurate and scientifically validated breastfeeding information from their attending physician (i.e., if homogeneous response patterns could be detected).

\section{Subjects}

The first survey set was collected from board-certified physicians in a Midwestern state. Hospitals within the geographical region supplied the mailing list that was used to identify 400 obstetricians/gynecologists, pediatricians, and family practitioners who were currently providing care for women across the state. The mailing list included physicians employed by the hospital as well as all physicians working in private practice in the community. 400 surveys were mailed to the physicians and 166 were returned (family practitioners $=124$, pediatricians $=23$, obstetricians and $/$ or gynecologists $=13$, general surgeons $=2$, and internists $=1$ ).

The second survey set was collected from women who were the mothers of infant children (i.e., 12 months of age or younger). Newspaper birth announcements across the Midwestern state provided the names and addresses of participants. 500 surveys were mailed to new mothers across the state and 193 were returned.

\section{Survey Design}

The surveys sent to the participants in this study (i.e., physicians and mothers of infants) were derived from The US Surgeon General's Blueprint for Action on Breastfeeding [31]. The questions contained in the surveys were worded exactly the same. However, with regard to physicians, the questions were worded "During the course of medical school training, I was informed..." while the surveys sent to the mothers were worded "My medical provider has informed me..." 11 Likert scaled questions were included to allow for degrees of agreement/disagreement. Each question was analyzed using a three-point Likert scale to indicate whether the participants were informed or not informed about the benefits of breastfeeding or whether they were unsure. The survey was designed to be brief, with completion to take no longer than 10 minutes.

\section{Survey Administration}

Surveys were sent to participants using First Class mail. A self-addressed, stamped envelope was included to increase the probability of a high response rate. The principal investigator included a signed cover letter. No follow-up surveys were sent and no telephone follow-up was employed. Data were collected over a 12-week period.

\section{Method of Analysis}

To determine if there was statistical homogeneity between the physician and women responses, $Z$-tests for a proportion were performed with statistical significance calculated at $P \leq 0.05$. Descriptive statistics regarding gender, physician specialty, age, income level, and insurance coverage were 
also calculated. This study was approved by the Institutional Review Board at the University of Nebraska-Kearney.

\section{Results}

Surveys were returned by 166 of the 400 physicians sampled (response rate was 41.5\%). Family practitioners accounted for $74.7 \%$, pediatricians $13.9 \%$, obstetricians $7.8 \%$, and general surgeons/internists/unreported specialization $3.6 \%$. $70.5 \%$ of the respondents were male, $27.7 \%$ were female, and $1.8 \%$ did not indicate gender. All participants were licensed to practice medicine in a Midwestern state.

Surveys were returned by 193 of the 500 women sampled (response rate was $38.6 \%$ ). The median age of participants was 25-30 years, and the median income level was 31,00050,000 . The majority of participants in this study were college graduates (58\%) and were covered by private health insurance (92\%). All participants were residents of a Midwestern state.

$Z$-test for a proportion was utilized to compare the responses of the physicians and the women who had given birth within the last year. Overall, statistical analyses revealed that the majority of physicians were informed during the course of medical school training of significant benefits associated with breastfeeding. However, the majority of women participating in this study reported that they were never informed of the numerous maternal and pediatric benefits associated with breastfeeding. Data indicated that physicians and women participants in this study had similar response patterns regarding childhood diabetes $(Z=1.10, P>$ $0.05)$, that breast milk contains anti-inflammatory factors that regulate the immune response against infections $(Z=$ $0.29, P>0.05)$, and that children who were breastfed are sick less often than children who are artificially fed $(Z=$ $0.43, P>0.05)$. Interestingly, data analysis revealed that the majority of physicians were not informed during the course of their medical school training that breastfeeding reduces the risks of certain types of childhood cancers, although women respondents reported that their attending physicians did inform them that breastfeeding reduces the incidence of childhood cancer $(Z=2.73, P<0.05)$. This finding is indeed perplexing and indicates that further research is needed to understand the lack of congruity between the physician and women responses.

Eleven identical survey questions were included for both physician and women respondents. Seven of the eleven questions indicated that while the majority of physicians reported that they were informed during the course of medical school training of the benefits of breastfeeding, women respondents indicated they were not informed of these benefits. The specific findings are as follows: breastfeeding reduces childhood ear infections $(Z=6.80, P<0.05)$, breastfeeding reduces the risk of childhood allergies $(Z=7.93, P<0.05)$, breastfeeding reduces childhood asthma $(Z=3.99, P<0.05)$, women who breastfeed have lower rates of ovarian cancer $(Z=3.59, P<0.05)$, breastfeeding can act as a natural contraceptive $(Z=7.18, P<0.05)$, breastfed children require fewer hospitalizations $(Z=7.78, P<0.05)$, and women who breastfed for 2 years or longer have a significantly lower risk of breast cancer $(Z=5.82, P<0)$ (See Table 1$)$.

\section{Discussion}

As with any investigation, it is important to note the limitations associated with this study. First, it must be acknowledged that retrospective reporting may not be entirely accurate. Physicians may find it difficult to recall specific medical school training, particularly if this training took place decades ago. Similarly, women participants may have trouble recalling all of the breastfeeding information they received from their attending physician. It is also a distinct possibility that women who are highly educated may ask more probing questions regarding infant feeding, thus leading physicians to discuss the many benefits associated with breastfeeding. Secondly, it is possible that those who are most interested in the topic of breastfeeding chose to return the surveys, thus inadvertently skewing the results. Thirdly, it is possible that physician self-reported breastfeeding education may have been over estimated in order to disguise the inadequacy of medical school training in the area of human lactation in the United States $[19,30]$. Finally, the generalizability of this study may be limited as data was collected from a Midwestern state.

Scholars from diverse fields have postulated that physicians (particularly family practitioners, obstetricians/gynecologists, and pediatricians) play an important role in increasing breastfeeding initiation and duration rates across diverse populations $[2,30,32]$. This study is unique in that it not only looks at what physicians are reporting, but also takes into account what women are reporting concerning specific physician breastfeeding advice. The majority of women participating in this study reported that they were not informed by their physician of the multitude of maternal and pediatric benefits associated with breastfeeding. If we are indeed serious about increasing breastfeeding rates, we must first address the question "why does the United States continually have one of the lowest breastfeeding rates in the world?" Collectively, we as a nation assert that we want what is best for our women and children, but are we willing to be proactive when it comes to increasing breastfeeding initiation and duration rates across the United States? As a first step, physicians, researchers, parents, policy makers, and concerned others must demand that scientifically validated breastfeeding information be disseminated to mothers via their medical provider as research clearly indicates that physicians exert considerable power when it comes to maternal feeding decisions $[1,2,32,33]$.

Results of this study indicate that physician respondents reported that they were aware that breastfeeding significantly decreases pediatric ear infections, allergies, asthma, and hospitalization, yet a significant number of the women participating in this study reported that they had not been informed of these benefits. Furthermore, data analysis revealed that there were significant differences detected with regard to what physicians and women reported concerning breastfeeding acting as a natural contraceptive and decreasing ovarian and 
TABLE 1

\begin{tabular}{|c|c|c|c|c|}
\hline Survey questions & Responders & Informed & $Z$-value & $P$ value \\
\hline \multirow{2}{*}{ Breastfeeding reduces risk of childhood diabetes } & Physician & $20.50 \%$ & \multirow[t]{2}{*}{-1.10} & \multirow[t]{2}{*}{0.2714} \\
\hline & Patient & $25.40 \%$ & & \\
\hline \multirow{2}{*}{$\begin{array}{l}\text { Breastfeeding reduces certain kinds of childhood } \\
\text { cancers }\end{array}$} & Physician & $15.10 \%$ & \multirow{2}{*}{-2.73} & \multirow[t]{2}{*}{$<0.05$} \\
\hline & Patient & $26.90 \%$ & & \\
\hline \multirow{2}{*}{ Breastfeeding reduces childhood ear infections } & Physician & $84.30 \%$ & \multirow{2}{*}{6.80} & \multirow{2}{*}{$<0.05$} \\
\hline & Patient & $50.30 \%$ & & \\
\hline \multirow{2}{*}{ Breastfeeding reduces risk of childhood allergies } & Physician & $88.60 \%$ & \multirow{2}{*}{7.93} & \multirow{2}{*}{$<0.05$} \\
\hline & Patient & $49.20 \%$ & & \\
\hline \multirow{2}{*}{ Breastfeeding reduces childhood asthma } & Physician & $62.00 \%$ & \multirow{2}{*}{3.99} & \multirow{2}{*}{$<0.05$} \\
\hline & Patient & $40.90 \%$ & & \\
\hline \multirow{2}{*}{$\begin{array}{l}\text { Children who are breastfed are sick less often than } \\
\text { children who are artificially fed }\end{array}$} & Physician & $86.60 \%$ & \multirow[t]{2}{*}{0.43} & \multirow[t]{2}{*}{0.6672} \\
\hline & Patient & $85.00 \%$ & & \\
\hline \multirow{2}{*}{$\begin{array}{l}\text { Women who breastfeed have lower rates of ovarian } \\
\text { cancer }\end{array}$} & Physician & $39.10 \%$ & \multirow[t]{2}{*}{3.59} & \multirow[t]{2}{*}{$<0.05$} \\
\hline & Patient & $21.80 \%$ & & \\
\hline \multirow{2}{*}{ Breastfeeding can act as a natural contraceptive } & Physician & $80.80 \%$ & \multirow[t]{2}{*}{7.18} & \multirow[t]{2}{*}{$<0.05$} \\
\hline & Patient & $42.50 \%$ & & \\
\hline \multirow[t]{2}{*}{ Breastfed children require fewer hospitalizations } & Physician & $58.80 \%$ & \multirow[t]{2}{*}{7.78} & \multirow[t]{2}{*}{$<0.05$} \\
\hline & Patient & $18.10 \%$ & & \\
\hline \multirow{2}{*}{$\begin{array}{l}\text { Breastfeeding for } 2 \text { years or more may reduce the } \\
\text { risk of breast cancer }\end{array}$} & Physician & $61.30 \%$ & \multirow[t]{2}{*}{5.82} & \multirow[t]{2}{*}{$<0.05$} \\
\hline & Patient & $30.60 \%$ & & \\
\hline \multirow{2}{*}{$\begin{array}{l}\text { Breast milk contains anti-inflammatory factors that } \\
\text { regulate the immune response against infections }\end{array}$} & Physician & $66.30 \%$ & \multirow{2}{*}{0.29} & \multirow[t]{2}{*}{0.7718} \\
\hline & Patient & $64.80 \%$ & & \\
\hline
\end{tabular}

breast cancer in maternal populations. In general, physicians reported that they were aware that breastfeeding decreases ovarian and breast cancer and that breastfeeding acts as a natural contraceptive, yet women participants reported that they were never informed of these vital medical facts.

According to the Surgeon General of the United States [1], breastfeeding significantly reduces pediatric morbidity rates and has been shown to protect maternal populations from a variety of pathological response patterns. Women have a fundamental right to be informed that breastfeeding (particularly exclusive and long-term breastfeeding) protects women and children from a multitude of serious illnesses and does in fact reduce maternal and pediatric mortality rates [1, $19,33]$. Decades of scientific data confirm that breastfeeding reduces childhood diabetes, cancer, ear infection, allergies, asthma, and hospitalization. In addition, epidemiological data has demonstrated that breastfeeding protects women from ovarian and breast cancer and is an effective means of birth control $[1,2,7,19]$. However, data from this study revealed that overall mothers are not receiving this important information from their physicians. Data from this study appears to support the Surgeon General's [1] hypothesis that one of the major contributing factors to America's low breastfeeding rates is physicians neglecting to inform their female patients of the multifarious benefits associated with breastfeeding in both maternal and pediatric populations.

Physicians that work primarily with women and children (i.e., family practitioners, OB/GYNS, and pediatricians) are in a unique position to promote, encourage, and support both the initiation and duration of breastfeeding [1]. According to the literature, pregnant women and mothers of infants report that physicians play a pivotal role in determining what type of feeding method to use, yet physicians have been found to underestimate the power they wield when it comes to increasing breastfeeding rates in their patients [32, 34].

According to published data, many women in the United States are not aware of the maternal and pediatric risks associated with formula feeding $[1,2,33]$. Walker [35] has postulated that medical providers neglect to inform their patients of the serious risks associated with formula feeding so as to alleviate maternal guilt. Walker also asserted that failing to inform female patients of medical facts generates 
more anger than guilt in patients who subsequently discover the risks associated with formula feeding at a later date.

Lawrence [19] states that parents have an inalienable right to be informed about the maternal and pediatric benefits associated with breastfeeding as well as the risks associated with formula feeding. Lawrence contends that withholding vital medical facts concerning the benefits of breastfeeding and the risks associated with formula feeding violates the right to informed consent-a critical component of the physician-patient relationship.

Other scholars in the field of human lactation take a somewhat different view with regard to the problem of physicians not informing their patients of the multitude of benefits associated with breastfeeding. Researchers have for decades postulated that women are not being informed of the risks associated with formula feeding and the benefits associated with breastfeeding because physicians in the United States of America are not being properly educated in the area of human lactation during the course of their medical school training $[29,30,33]$.

Results of this study indicate that while physicians are reporting that they are aware of many of the maternal and pediatric benefits associated with breastfeeding, women participants are reporting that they are not being informed by their physician of the compendious protective factors associated with breastfeeding. Decades of scientific data clearly indicate that physicians have the power to significantly increase breastfeeding initiation and duration rates by providing their patients with medically substantiated breastfeeding facts $[1,33,34]$. Scholars across diverse fields have suggested that in order to significantly increase breastfeeding rates across America, the following guidelines must be implemented.

(1) Include comprehensive breastfeeding education throughout medical school training $[1,30]$.

(2) Incorporate lactational consultants with residency training (i.e., include consultants on postpartum and newborn rounds) $[29,30]$.

(3) Inform patients that formula feeding and breastfeeding are not equal methods of feeding and that there are quantifiable risks associated with formula feeding $[2,33]$.

(4) Demand mandatory continuing breastfeeding education to practicing physicians $[29,30,33]$.

(5) Inform patients that there is a difference between adequate and optimal development $[2,35]$.

(6) Inform physicians of the tremendous power they exert regarding maternal feeding decisions, and demand that the doctrine of informed consent be fully enforced [19].

(7) Eliminate the promotion and advertising of formula, particularly in physicians' offices, hospitals, parenting magazines, and medical journals [36].

(8) Inform patients of the numerous maternal and child benefits associated with breastfeeding [12, 37].
(9) Inform female patients that the most significant benefits associated with breastfeeding occur with exclusive and long-term breastfeeding [1].

(10) Inform patients of the increased medical expenses associated with formula feeding (i.e., increased doctor visits, prescription drug use, and hospitalization) $[1,8]$.

\section{Conclusion}

In summary, the findings contained within this study suggest that the majority of physicians are aware of many of the protective effects associated with breastfeeding. However, statistical analyses revealed that the majority of women participating in this study did not receive compendious breastfeeding information from their attending physician. Family practitioners, obstetrician/gynecologists, and pediatricians are most likely to influence maternal feeding decisions [1]; thus it is crucial that physicians in these particular areas understand the power associated with their position and act according to the guidelines set forth by the Surgeon General of the United States [1]. While it is encouraging to note that physicians participating in this study did inform their patients that breastfeeding decreases childhood diabetes, that it contains anti-inflammatory factors that regulate immune response against infections, and that breastfed children are sick less than children who are formula fed, the fact remains that significant deficits were detected throughout this investigation. It is absolutely imperative that women are informed by their medical provider about the multifarious protective factors associated with breastfeeding in maternal and pediatric populations so that women can make educated decisions regarding infant feeding practices.

Lastly, the authors recognize the urgent need for further research to elucidate the social, cultural, economic, and psychological factors that are associated with America's low breastfeeding rates across time and across diverse populations. One thing is for certain: women have a fundamental right to be informed of the numerous maternal and pediatric risks associated with formula feeding. Perhaps the time has come to demand that the doctrine of informed consent is fully implemented as enforcement of this doctrine would most certainly increase both the initiation and duration of breastfeeding and, in turn, would improve maternal and child health outcomes exponentially across America.

\section{Conflict of Interests}

The authors declare that there is no conflict of interests regarding the publication of this paper.

\section{References}

[1] United States Department of Health and Human Services, The Surgeon General's Call to Action to Support Breastfeeding, United States Department of Health and Human Services, Washington, DC, USA, 2011. 
[2] American Academy of Pediatrics (AAP), "Policy statement: breastfeeding and the use of human milk," Pediatrics, vol. 115, no. 2, p. 496, 2012.

[3] R. Schanler, K. O'Connor, and R. Lawrence, "Pediatrician'practices and attitudes regarding breastfeeding promotion," Pediatrics, vol. 103, no. 3, pp. E35-E38, 1999.

[4] K. Dewey, M. Heinig, and L. Nommsen-Rivers, "Differences in morbidity between breast-fed and formula-fed infants," The Journal of Pediatrics, vol. 126, no. 5, pp. 696-702, 1995.

[5] J. Golding, M. Paterson, and L. Kinlen, "Factors associated with childhood cancer in a national cohort study," British Journal of Cancer, vol. 62, no. 2, pp. 304-309, 1990.

[6] M. Kwan, P. Buffler, B. Abrams, and V. Kiley, "Breastfeeding and the risk of childhood leukemia: a meta-analysis," Public Health Reports, vol. 119, no. 6, pp. 521-528, 2004.

[7] A. Sonnenschein-van der Voort and L. Duijts, "Breastfeeding is protective against early childhood asthma," Evidence Based Medicine for Primary Care and Internal Medicine, vol. 1, pp. 6071, 2012.

[8] T. Ball and A. Wright, "Health care costs of formula-feeding in the first year of life," Pediatrics, vol. 103, no. 4, pp. 870-876, 1999.

[9] M. Bartick and A. Reinhold, "The burden of suboptimal breastfeeding in the United States: a pediatric cost analysis," Pediatrics, vol. 125, no. 5, pp. e1048-e1056, 2010.

[10] C. Delgado and A. Matijasevich, "Breastfeeding up to two years of age or beyond and its influence on child growth and development: a systematic review," Cadernos de Saúde Pública, vol. 29, no. 2, pp. 1480-1485, 2013.

[11] E. Mortensen, K. Michaelson, S. Sanders, and J. Reinisch, "The association between duration of breastfeeding and adult intelligence," Journal of the American Academy of Child \& Adolescent Psychiatry, vol. 41, no. 11, pp. 38-41, 2003.

[12] B. Dennison, "Public policy to improve child nutrition and health challenges and opportunities," Archives of Pediatrics \& Adolescent Medicine, vol. 166, no. 5, pp. 485-487, 2012.

[13] H. Kato, O. Inoue, T. Kawasaki, H. Fujiwara, T. Watanabe, and H. Thoshima, "Adult coronary artery disease probably due to childhood Kawasaki disease," The Lancet, vol. 340, no. 8828, pp. 1127-1129, 1992.

[14] P. Jeurink, J. Bergenhenegouwen, E. Jimenez et al., "Human milk: a source of more life than we imagine," Beneficial Microbes, vol. 4, no. 1, pp. 17-30, 2013.

[15] S. Koletzko, P. Sherman, M. Corey, A. Griffiths, and C. Smith, "Role of infant feeding practices in development of Crohn's disease in childhood," British Medical Journal, vol. 298, no. 6688, pp. 1617-1619, 1989.

[16] A. Schneider, "Risk factor for ovarian cancer," The New England Journal of Medicine, vol. 317, no. 8, pp. 508-510, 1987.

[17] H. Weis, N. Postischman, and L. Brinton, "Prenatal and postnatal risk for breast cancer in young women," Epidemiology, vol. 8, no. 2, pp. 181-187, 1997.

[18] J. Freudenheim, J. Marshall, S. Graham et al., "Exposure to breastmilk in infancy and the risk of breast cancer," Epidemiology, vol. 5, no. 3, pp. 324-330, 1994.

[19] R. Lawrence, Breastfeeding: A Guide for the Medical Profession, Mosby, St. Louis, Mo, USA, 4th edition, 2005.

[20] F. Mancini, C. Carlson, and L. Albers, "Use of postpartum depression screening scale in a collaborative obstetric practice," Journal of Midwifery \& Women's Health, vol. 52, no. 5, pp. 429434, 2007.
[21] C. Dennis and K. McQueen, "The relationship between infantfeeding outcomes and postpartum depression: a qualitative systematic review," Pediatrics, vol. 123, no. 4, pp. e736-e751, 2009.

[22] T. Insel and L. Shapiro, "Oxytocin receptors and maternal behavior," Annals of the New York Academy of Sciences, vol. 652, pp. 122-141, 1992.

[23] N. Newton, "The uniqueness of human milk: psychological differences between breast and bottle feeding," The American Journal of Clinical Nutrition, vol. 24, no. 8, pp. 993-1000, 1971.

[24] A. McNeilly, "Lactational amenorrhea," Endocrinology and Metabolism Clinics of North America, vol. 22, no. 1, pp. 59-73, 1993.

[25] H. Sipsma, E. Bradley, and P. Chen, "Lactational amenorrhea method as a contraceptive strategy in Niger," Maternal and Child Health Journal, vol. 2, pp. 51-60, 2012.

[26] J. Bongaarts, "A framework for analyzing the proximate determinants of fertility," Population and Development Review, vol. 4, no. 1, pp. 105-130, 1978.

[27] M. Konner and C. Worthman, "Nursing frequency, gonadal function, and birth spacing among the Kung hunter-gatherers," Science, vol. 207, no. 4432, pp. 788-802, 1980.

[28] R. Gray, O. Campbell, R. Apelo et al., "Risk of ovulation during lactation," The Lancet, vol. 335, no. 8680, pp. 25-29, 1990.

[29] R. Lawrence, "Challenges to successful breastfeeding," Breastfeeding Medicine, vol. 7, no. 1, pp. 15-17, 2012.

[30] G. Freed, S. Clark, P. Curtis, and J. Sorenson, "Breast-feeding education and practice in family medicine," The Journal of Family Practice, vol. 40, no. 3, pp. 263-268, 1995.

[31] United States Department of Health and Human Services, The Blueprint for Action on Breastfeeding, United States Department of Health and Human Services, Washington, DC, USA, 2000.

[32] E. Taveras, L. Grummer-Strawn, M. Richardson, R. Marshall, and V. Rego, "Opinions and practices of clinicians associated with continuation of exclusive breastfeeding," Pediatrics, vol. 113, no. 4, pp. e283-e290, 2004.

[33] J. Stolzer and S. Hossain, "Women, physicians, and breastfeeding advice: a regional analysis," Ethics \& Medicine, vol. 22, no. 3, pp. 182-187, 2006.

[34] K. Szucs, D. Miracle, and M. Rosenman, "Breastfeeding knowledge, attitudes, and practices among providers in a medical home," Breastfeeding Medicine, vol. 4, no. 1, pp. 31-42, 2009.

[35] M. Walker, "A fresh look at the risks of artificial infant feeding," Journal of Human Lactation, vol. 9, no. 2, pp. 97-103, 1993.

[36] J. Stolzer and S. Hossain, "Physician breastfeeding education: a regional assessment," The Female Patient, vol. 30, pp. 16-21, 2005.

[37] United States Department of Health and Human Services, Healthy People 2000, United States Department of Health and Human Services, Washington, DC, USA, 2000. 

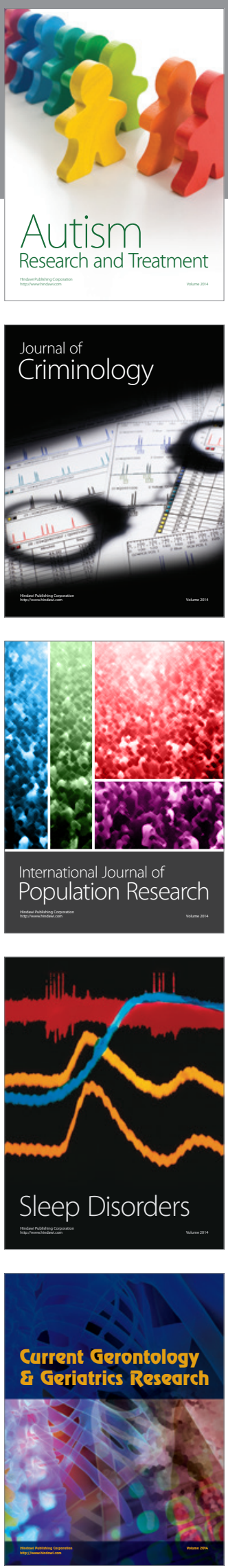
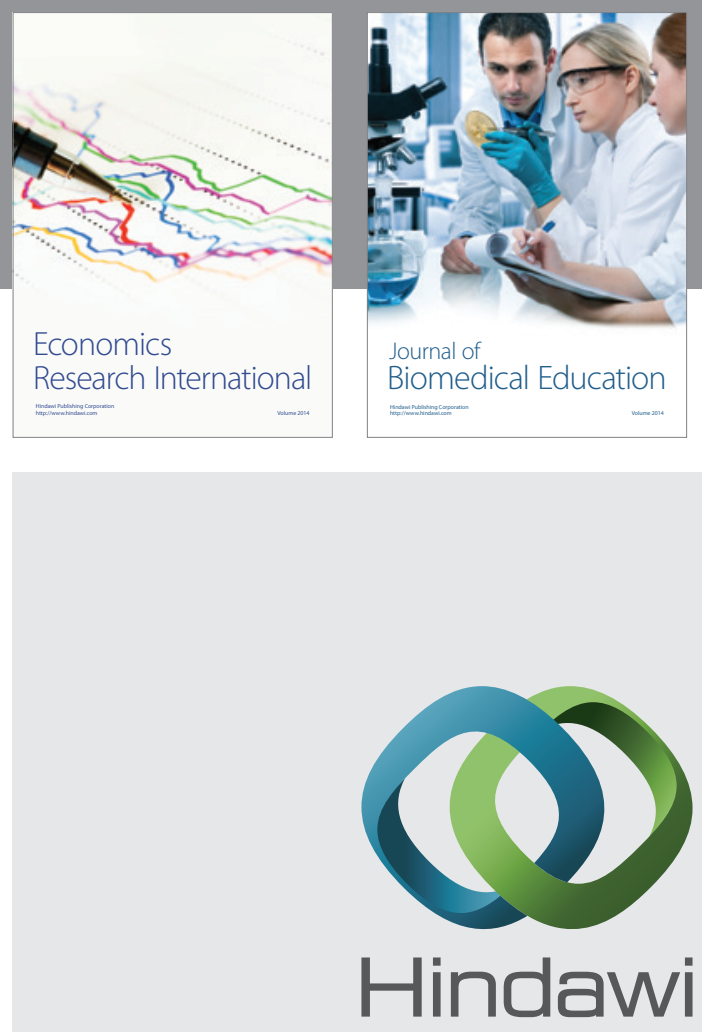

Submit your manuscripts at

http://www.hindawi.com
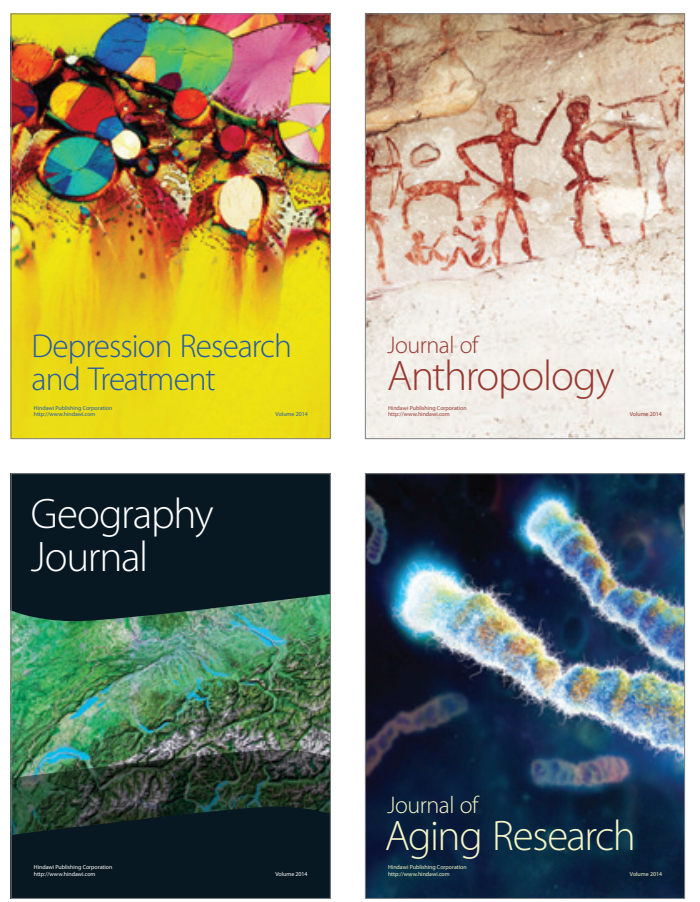
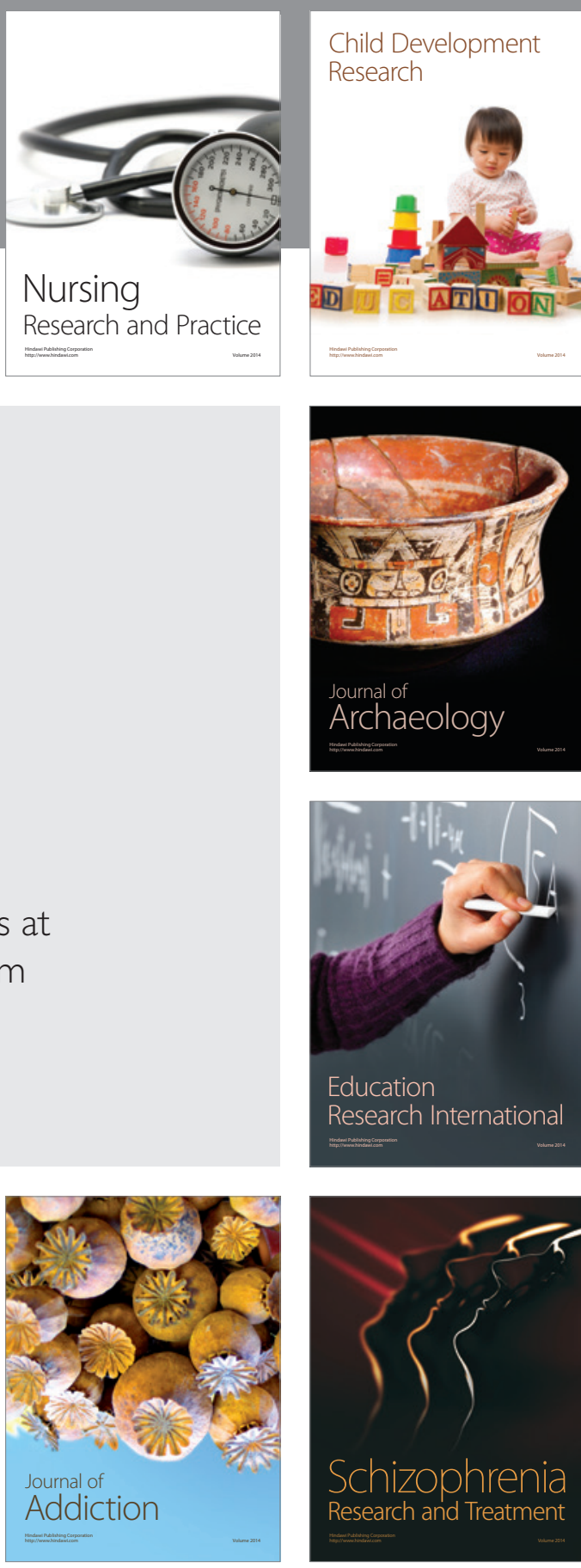

(D)
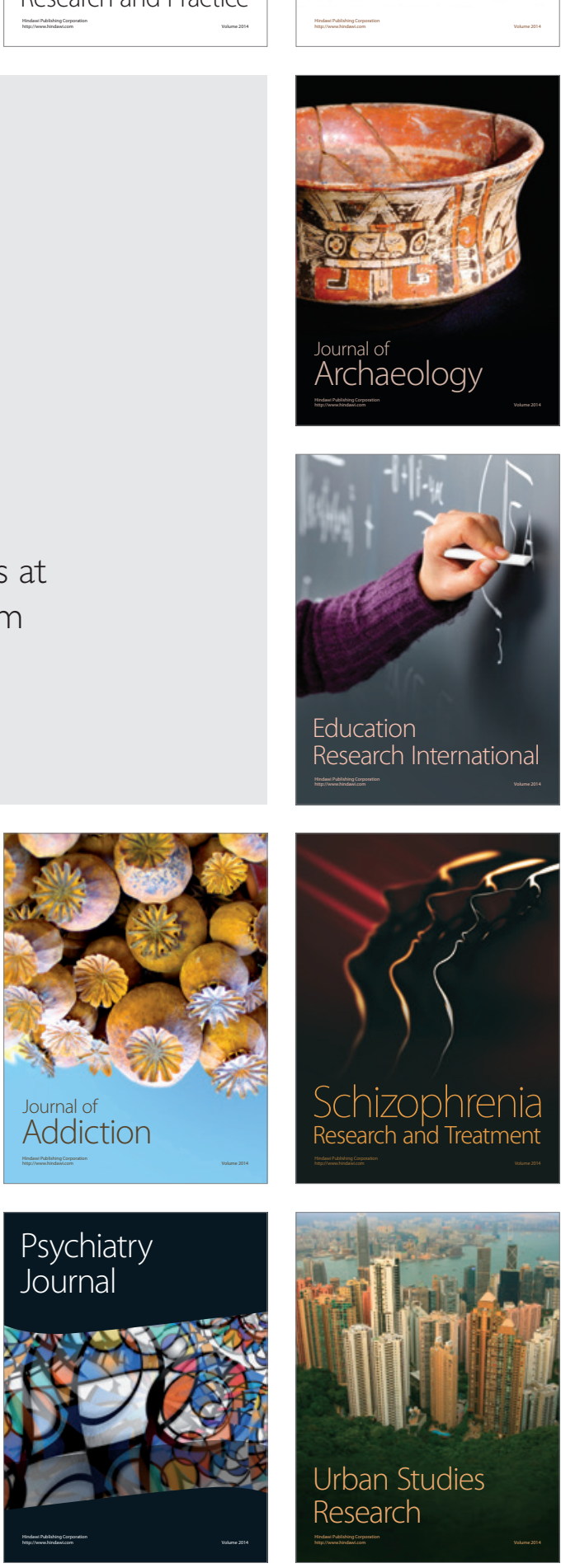